\title{
The Effect of Kinesiotaping on Pain, Functionality and Ultrasound Parameters in Patients with Shoulder Impingement Syndrome: A Randomised Sham-controlled Study
}

\author{
Omuz Sıkısma Sendromlu Hastalarda Kinezyobantlamanın Ağrı, Fonksiyonellik ve \\ Ultrason Parametreleri Üzerine Etkisi: Randomize Sham-kontrollü Bir Çalışma
}

\begin{abstract}
(D) Fatih Bağcıer, (D) Duygu Geler Külcü*, (D) Nilgün Mesci*, (D) Mustafa Hüseyin Temel*
Biruni University Faculty of Medicine, Departmant of Physical Medicine and Rehabilitation, İstanbul, Turkey

*University of Health Sciences Turkey, Istanbul Haydarpaşa Numune Training and Research Hospital, Clinic of Physical Medicine and Rehabilitation,
\end{abstract}

istanbul, Turkey

\section{Abstract}

Objective: We investigated the effect of kinesiotaping on pain, functionality and ultrasound parameters in patients with shoulder impingement syndrome (SIS).

Materials and Methods: Seventy-five patients with SIS were randomly classified into the following three groups: Kinesiotaping (KT), conventional exercise (CE) and sham-kinesiotaping (sham-KT). Each group underwent a two-week treatment programme. The patients were then evaluated in terms of pain analysed using the visual analogue scale (VAS), joint range of motion and disabilities of the arm, shoulder and hand (DASH) questionnaire, before and after treatment. In addition, the supraspinatus tendon (SsT) thickness and acromiohumeral distance (AHD) parameters were measured using ultrasonography (US).

Results: There was a statistically significant difference between the groups in terms of post-treatment VAS scores obtained at night and during activity. According to the post-hoc analysis, these differences were observed in the CE group ( $p<0.016)$. Because there was a difference in the pre-treatment DASH scores between the groups, the groups were examined for changes in the DASH score before and after treatment; a significant difference between sham-KT and KT groups and between sham-KT and CE groups favouring KT and CE groups was observed. US revealed that the CE group was superior to the sham-KT group in terms of both reduction in SsT thickness and increase in $A H D(p<0.016)$. Furthermore, KT was effective in increasing AHD.

Conclusion: KT was superior to sham-KT in terms of all parameters except pain. KT was also found to be as effective as CE in all parameters. In addition, US objectively revealed that the supraspinatus tendinitis can be reduced and AHD can be increased. KT is an alternative treatment option in patients with SIS and can be used alone or in combination with CE in patients who do not comply with CE.

Keywords: Kinesiotaping, shoulder impingement syndrome, ultrasound

\section{Öz}

Amaç: Omuz impingement (sıkışma) sendromu (OiS) olan hastalarda kinezyobantlamanın (KT) ağrı, fonksiyonellik ve ultrason parametreleri üzerine etkisini araştırmayı amaçladık.

Gereç ve Yöntem: Toplam 75 Ois hastası randomize olarak üç grupta sınıflandııılı: KT, konvansiyonel egzersiz (KE) ve sham-kinezyobantlama (sham-KT). Her gruba iki haftalık tedavi programı uygulandı. Hastalar tedavi öncesi ve sonrası görsel analog skala (GAS), eklem hareket açıklığı, kol, omuz ve el sorunları (DASH) anketi kullanılarak değerlendirildi. Ayrıca supraspinatus tendonu (SsT) kalınlığı ve akromiohumeral mesafe (AHM) parametreleri ultrasonografi (US) kullanılarak ölçüldü.

Bulgular: Gruplar arasında tedavi sonrası gece ve aktivite-GAS skorları açısından istatistiksel olarak anlamlı fark vardı. Post-hoc analize göre, bu farklılıklar KE grubu lehine gözlenmiştir $(p<0,016)$. Gruplar arasında tedavi öncesi DASH skorlarında bir fark olduğu için, gruplar tedavi Öncesi ve sonrası DASH skorundaki değişiklikler açısından incelendi; sham-KT ve KT ile sham-KT ve KE grupları arasında KT ve KE grupları lehine anlamlı bir fark tespit edilmiştir. US, KE grubunun hem SsT kalınlığındaki azalma hem de AHD'deki artış açısından sham-KT grubundan daha üstün olduğunu ortaya koymuştur $(p<0,016)$. Ayrıca, KT AHD'nin artmasında etkili olmuştur.

Sonuç: KT, ağrı dışındaki tüm parametrelerde sham-KT'den üstün görülmüştür. KT'nin tüm parametrelerde KE kadar etkili olduğu bulunmuştur. Ek olarak, US nesnel olarak supraspinatus tendinitinin azaltılabileceğini ve AHD'nin artırılabileceğini ortaya koymuştur. KT, Ois'li hastalarda alternatif bir tedavi seçeneğidir ve KE ile uyumlu olmayan hastalarda tek başına veya KE ile kombinasyon halinde kullanılabilir.

Anahtar kelimeler: Kinezyobantlama, omuz sıkısma sendromu, ultrason

Address for Correspondence/Yazışma Adresi: Fatih Bağcıer MD, Biruni University Faculty of Medicine, Departmant of Physical Medicine and Rehabilitation, İstanbul, Turkey Phone: +90 5442429042 E-mail: bagcier_42@hotmail.com ORCID ID: orcid.org/0000-0002-6103-7873 Received/Geliş Tarihi: 02.01.2020 Accepted/Kabul Tarihi: 16.04.2020

${ }^{\circ}$ Copyright 2020 by the Turkish Osteoporosis Society / Turkish Journal of Osteoporosis published by Galenos Publishing House. 


\section{Introduction}

Shoulder impingement syndrome (SIS) is one of the most common causes of shoulder pain (1). Shoulder pain associated with SIS ranges from simple pathologies such as subacromial bursitis to rotator cuff tendinopathy and full fold tear (2). Conservative treatment methods include non-steroidal antiinflammatory drugs, steroid injections to the subacromial region, physical therapy modalities, and conventional exercise (CE) (3-5). Kinesiotaping (KT) has recently become more widespread and has been used to treat various musculoskeletal pathologies $(6,7)$. Studies have shown that KT reduces pain and increases the range of motion (ROM) in SIS, particularly in the early period (8). Kinesiotape is an advantageous method as it is non-invasive and can be applied easily and in a short time (8). Clinical parameters have been used for evaluation in previous studies comparing the effectiveness of KT (8). The aim of the current study, was to compare the efficacy of KT with both sham application and exercise therapy using ultrasonographic measurements as objective data in addition to clinical parameters.

\section{Materials and Methods}

\section{Participants}

The study included patients aged 45-70 years who were admitted to our outpatient clinic with complaints of shoulder pain, were diagnosed with SIS based on physical examination and magnetic resonance imaging results, and were eligible based on the inclusion and exclusion criteria. The inclusion criteria were as follows: (1) at least three positive results in the Hawkins-Kennedy, Neer, empty can, drop-arm, and lift-off tests, (2) magnetic resonance imaging findings, and (3) age between 45 and 70 years. Patients were excluded from the study if they had received physical therapy for the shoulder region within the past three months, had a history of injections to the shoulder joint, had any cervical pathologies, clinical conditions accompanied by neuromotor or sensory dysfunction, a history of malignancy, were pregnant, had a partial or total rupture in the supraspinatus tendon (SsT), adhesive capsulitis, diabetes, chronic liver disease, or kidney failure. Demographic data (age, gender, dominant side, disease duration, and occupational status) were recorded at the beginning of the study.

All patients provided written consent prior to study initiation. The details of the numbers of included and excluded patients through to the final data analysis are shown in Figure 1 as a flowchart. Approval for the study was granted by the Haydarpaşa Numune Training and Research Hospital Clinical Research Ethics Committee (decision no: HNEAH-KAEK 2016/98).

\section{Design}

This prospective, randomized, single-blind trial was conducted at a single center between April 2017 and October 2017. A total of 75 patients were included in the study and were randomly assigned to one of the following three groups using a table of random numbers: KT, CE, and sham-KT groups. The study was completed with no drop-outs.

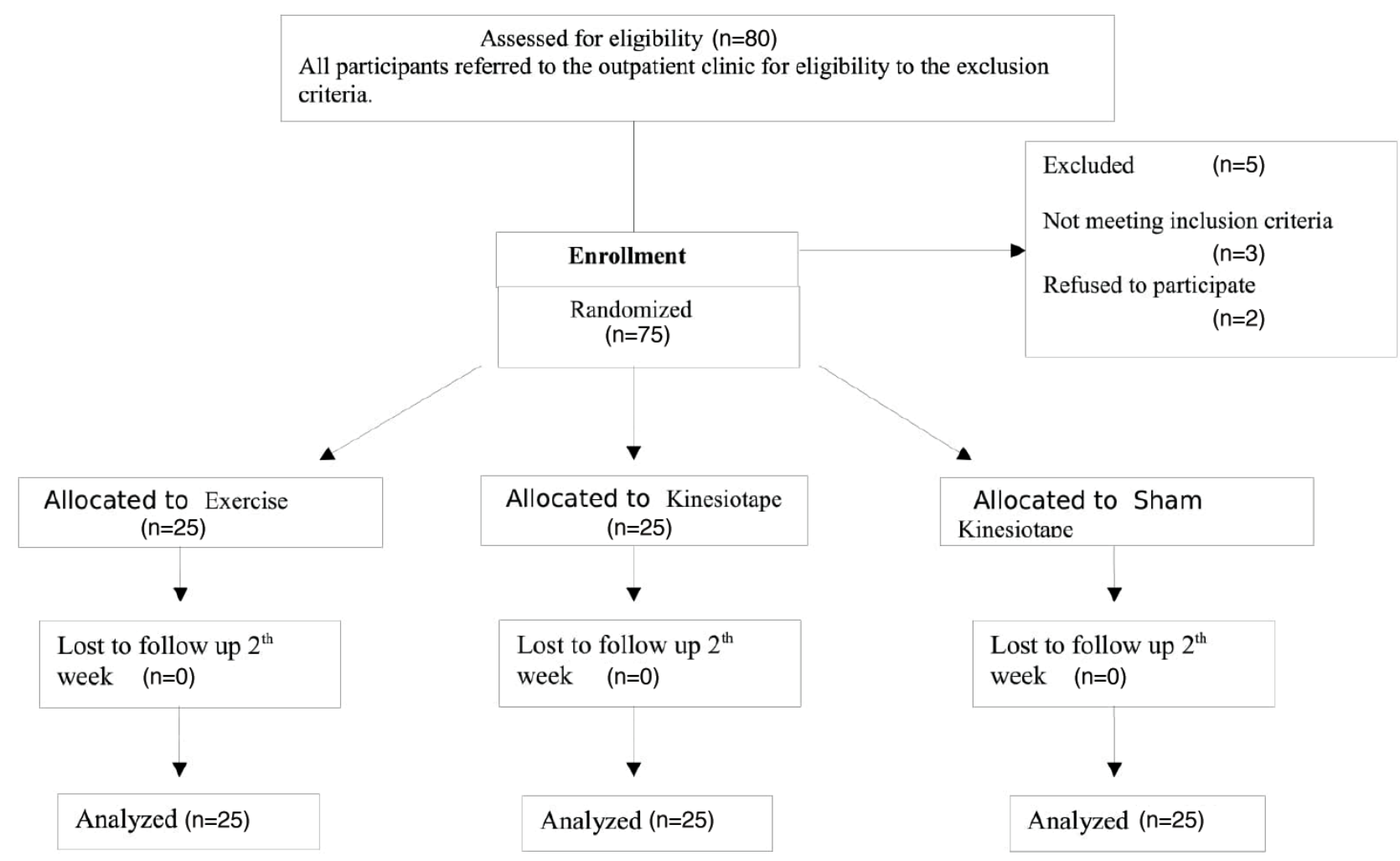

Figure 1. Flow diagram for study participants 
All participants were assessed by the same clinician (F.B.) at baseline and at 2 weeks after completing the interventions using a visual analog scale (VAS), ROM and disabilities of the arm, shoulder and hand (DASH) questionnaire. All the KT and sham-KT applications were made by a single clinician who was blinded to the group allocation (N.M.). The ultrasonographic (US) measurements were taken by a single clinician (D.G.K.), who was blinded to the group allocation.

In the power analysis, based on the VAS score determined during activity and considering a dropout rate of $20 \%, 25$ patients in each group were expected to result in a $5 \%$ type 1 error rate. The power of the test was expected to be $80 \%$. MedCalc Statistical Software version 12.7.7 (MedCalc Software Bvba, Ostend, Belgium; http://www.medcalc.org; 2013) was used for these measurements.

\section{Interventions}

Group 1: Cold application, KT treatment (2 sessions with a 5-day interval)

Group 2: Cold application, CE treatment (3 sessions per day for 2 weeks)

Group 3: Cold application, sham-KT treatment (2 sessions with a 5-day interval)

\section{Treatments Applied to the Patients}

Cold application: At the beginning of each treatment session, gel ice packs were wrapped in a damp towel and applied to the affected shoulder joint for 20 minutes.

Group 1: KT was applied to the deltoid muscle using the inhibition and mechanical correction technique and to the supraspinatus muscle using the inhibition technique (Two sessions with a 5-day interval) (9).

Deltoid muscle inhibition technique: The Y-shaped kinesiotape was applied $3 \mathrm{~cm}$ below the deltoid tuberosity of the humerus without tension. The Y-band was applied to the forearm with $15 \%-25 \%$ light stretching along the outer edge of the anterior deltoid up to the acromioclavicular joint and with 15\%-25\% light stretching along the outer edge of the posterior deltoid up to lateral aspect of the acromion. The last $3-5 \mathrm{~cm}$ of the tails was applied to the adhesion sites without any tension. When performing the procedure, the shoulder was maintained in transverse extension and external rotation (ER) for the forearm of the Y-strip and $45^{\circ}$ of transverse flexion (FLX) and horizontal adduction for the posterior arm of the Y-strip (Figure 2a).

Supraspinatus muscle inhibition technique: The Y-shaped kinesiotape was applied $3 \mathrm{~cm}$ below the greater tubercle of the humerus without tension. The patient was instructed to adduct the shoulders simultaneously bringing the neck to lateral FLX on the opposite side. The initial section of the tape was adhered to the greater tubercle below the acromion with submaximal (75\%) tension. The lower arm of the Y-strip was applied to the medial edge of the scapula along the spina scapula without tension. The upper arm was applied to the spina scapula superior between the upper and lower trapezoidal muscles along the medial edge of the scapula in the supraspinatus fossa without stretching. The shoulder was in protraction and internal rotation (IR) during the application (Figure 2b).

Mechanical correction technique: The Y-shaped kinesiotape was applied with the arm in the neutral position along the torso. The application was started from the coracoid process without stretching. The upper arm of the Y-strip was applied over the acromioclavicular joint to the outer edge of the posterior deltoid with maximal stretching, with the last $3-5 \mathrm{~cm}$ applied without any stretching; the lower arm of the Y-strip was applied several centimeters below the upper arm with the same technique (Figure 2c).

Group 2: CE treatment was administered for 10 days with 3 sessions/day. A triphasic exercise program was administered to the patients. Before starting the exercise program, the patients were instructed not to perform overhead movements exceeding $90^{\circ}$. The exercise program was initiated using Codman pendulum, passive joint motion range (with a 1-m stick), and posterior capsule stretching exercises. Shoulder wheel, finger ladder, and shoulder strengthening exercises using a theraband were added to the exercise programs of patients with full or near total ROM and pain relief. Exercise was administered twice a week under supervision and the patients were advised to exercise at home on the other days with 20 repetitions of each exercise. The patients were followed up via telephone to make sure they were adhering to the exercise program (10).

Group 3: Sham-KT was applied in $10 \mathrm{~cm}$ l-shaped strips on the sagittal plane over the acromioclavicular joint without stretching and on the transverse plane distal to the deltoid area. The kinesiotape was applied twice with a 5-day interval (Figure 2d).

\section{Evaluation Parameters}

All patients were evaluated before and after treatment.

1. Pain level: The severity of shoulder pain (resting, activity, and night pain) of the patients was evaluated using the VAS score. The patients were asked to mark the average severity of the pain they felt during the past week on a $10 \mathrm{~cm}$ ruler, where 0:no pain and 10: the most severe pain. The marked points were recorded.

2. Functional status: DASH questionnaire comprises three sections. The first section includes 30 items: 21 items assess the patient's difficulties in performing daily activities, 5 assess symptoms (pain, activity-related pain, tingling, stiffness, and weakness), and each of the remaining 4 items assesses social function, work, sleep, and self-confidence. All items are rated on a 5-point Likert-type scale (1: no difficulty, 2: mild difficulty, 3: moderate difficulty, 4: extreme difficulty, 5: cannot perform at all). The total score ranges from 0 to 100 (0: no disability, 100: maximum disability). Turkish reliability and validity studies have been performed for this questionnaire (11).

3. Joint range of motion measurements: FLX, abduction $(A B D), I R$ and ER were measured using a goniometer (Saehan goniometer - plastic).

4. Ultrasonography: US was performed using a $7.5-\mathrm{mHz}$ linear probe in the B mode (Mindray-China). SsT thickness was 
measured at three different points $(10,15$, and $20 \mathrm{~mm}$ ) lateral to the tendon after identifying the biceps tendon in the transverse section and the average of measurements was recorded (Figure 3a). Acromiohumeral distance (AHD) was assessed by measuring the linear distance between the inferior of the acromion from the anterior of the shoulder and the superior of the humeral head (Figure 3b) (12).

\section{Statistical Analysis}

All analyses were performed using the MedCalc Statistical Software version 12.7.7 (MedCalc Software bvba, Ostend, Belgium; http://www.medcalc.org; 2013). Descriptive statistics were used to describe continuous variables (average, standard deviation, minimum, median, and maximum values). Conformity of the data to normal distribution was assessed with the Kolmogorov-Smirnov test. As the data were not normally distributed, the relationship between two dependent continuous variables was investigated using the Wilcoxon Signed Rank test, and the Kruskal-Wallis test was used to compare continuous variables among many groups. In cases where the Kruskal-
Wallis test revealed a significant difference, post-hoc analysis was conducted using the Mann-Whitney $U$ test with Bonferroni correction. A value of $p<0.016$ was considered statistically significant.

The correlation between dependent and categorical variables was examined using the McNemar test. The chi-square or Fisher's Exact test, as appropriate, was used to examine the correlation between independent categorical variables. The comparison of two independent variables was performed using the Mann-Whitney $U$ test. The level of statistical significance was set at $p<0.05$.

\section{Results}

1. Demographic data: No significant difference was determined between the groups in terms of demographic characteristics (Table 1).

2. Pain parameters: VAS: No difference was determined between the groups in respect of the resting, activity and nightVAS scores before treatment. In the post- treatment night- and
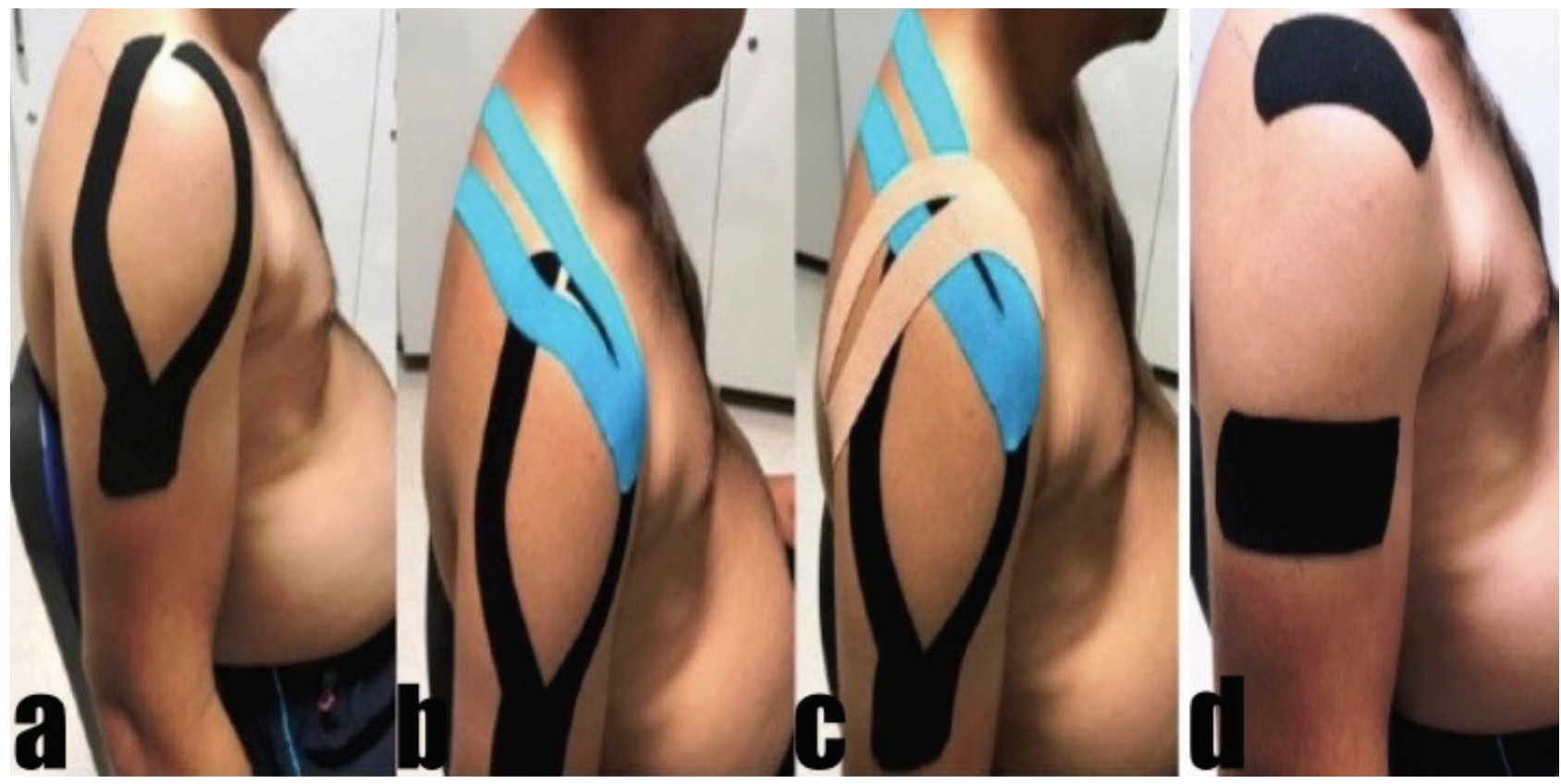

Figure 2. Application of kinesiotaping. (a) Deltoid muscle inhibition technique; (b) supraspinatus muscle inhibition technique; (c) deltoid muscle mechanical correction technique; (d) sham application technique

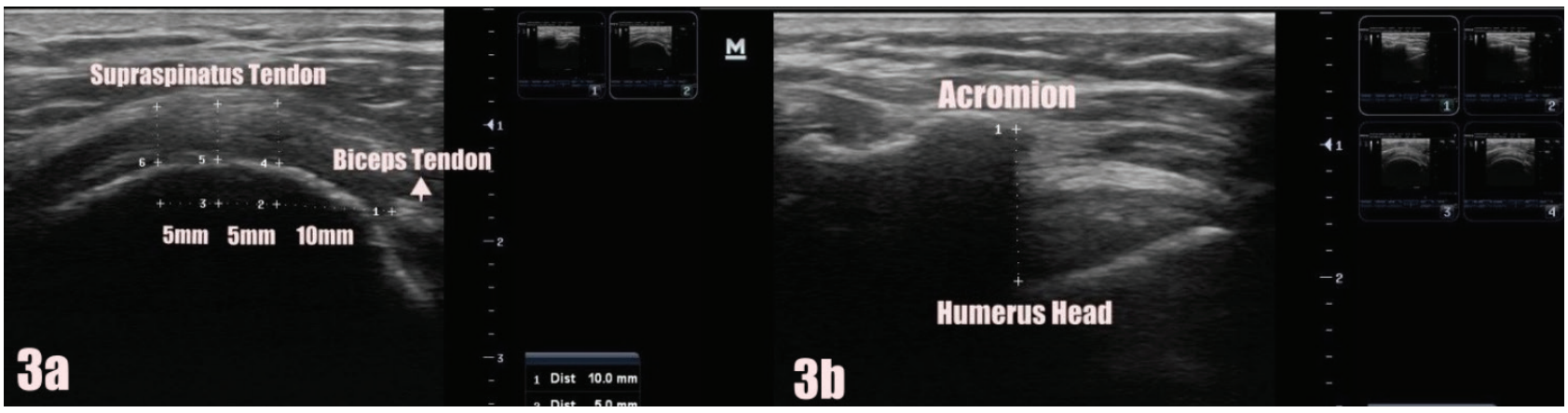

Figure 3. (a) Ultrasonographic measurement of supraspinatus tendon thickness. (b) Ultrasonographic measurement of acromiohumeral distance 
activity-VAS scores, a statistically significant difference was determined between the groups. According to the post-hoc analysis, these differences were found between the sham-KT and CE groups and in favor of the CE group $(p<0.016)$ (Table 2).

3. Functional status: As there was a difference between the groups in the pre-treatment DASH scores, the changes in DASH scores after treatment were examined in terms of differences between the groups. A significant difference was found between the sham-KT and KT groups and between the sham-KT and CE groups in favor of the KT and CE groups, respectively (Table 2).

4. Joint range of motion measurements: Pre-treatment, there was no difference between the groups in terms of joint ROM in all directions. Following treatment, a statistically significant difference was determined between the groups in respect of the FLX angles. According to the post-hoc analysis, this difference was found between the sham-KT and KT groups and between the sham$\mathrm{KT}$ and CE groups in favor of the KT and CE groups, respectively $(p<0.016)$ (Table 3). There were statistically significant differences between the groups in terms of the post-treatment ABD and ER angles. According to the post-hoc analysis, this difference was found between the sham-KT and CE groups in favor of the CE group ( $p<0.016)$. There was no difference between the groups in terms of the post-treatment IR angles.

5. Ultrasonographic measurements: As there was a difference between the groups in terms of the pre-treatment SsT thickness and AHD measurements, it was analyzed

\begin{tabular}{|c|c|c|c|c|c|}
\hline \multicolumn{2}{|l|}{ Parameters } & KT group $(n=25)$ & CE group $(n=25)$ & Sham-KT group $(n=25)$ & ap \\
\hline \multirow{2}{*}{ Dominant side, n (\%) } & Right & $24(96 \%)$ & $25(100 \%)$ & $23(92 \%)$ & 0.769 \\
\hline & Left & $1(4 \%)$ & $0(0.0)$ & $2(8 \%)$ & - \\
\hline \multirow{2}{*}{ Patient side, n (\%) } & Right & $17(68 \%)$ & $17(68 \%)$ & $14(56 \%)$ & 0.717 \\
\hline & Left & $8(32 \%)$ & $8(32 \%)$ & $11(44 \%)$ & - \\
\hline \multirow{2}{*}{ Gender, n (\%) } & Woman & $16(64 \%)$ & $15(60 \%)$ & $19(76 \%)$ & 0.555 \\
\hline & Man & $9(36 \%)$ & $10(40 \%)$ & $6(24 \%)$ & - \\
\hline \multirow{4}{*}{ Occupation, n (\%) } & Housewife & $10(40 \%)$ & $11(44 \%)$ & $15(60 \%)$ & 0.104 \\
\hline & Retired & $5(20 \%)$ & $9(36 \%)$ & $6(24 \%)$ & - \\
\hline & Civil servant & $5(20 \%)$ & $0(0.0)$ & $0(0.0)$ & - \\
\hline & Worker & $5(20 \%)$ & $5(20 \%)$ & $4(16 \%)$ & - \\
\hline Age, years, range & & $50(46-70)$ & $58(52-70)$ & $56(54-70)$ & b0.571 \\
\hline $\mathrm{BMI},\left(\mathrm{kg} / \mathrm{m}^{2}\right)$, range & & $27(17-35)$ & $26(21-36)$ & $27(15-37)$ & 0.952 \\
\hline
\end{tabular}

\section{Table 2. Visual analogue scale and the disabilities of the arm, shoulder and hand scores at pre- post-treatment visit}

\begin{tabular}{|l|l|l|l|l|}
\hline \multirow{2}{*}{ Parameters } & KT group (n=25) & CE group (n=25) & Sham-KT group (n=25) & ap \\
\cline { 2 - 5 } & Median (min-max) & Median (min-max) & Median (min-max) & $5(0-10)$ \\
\hline VAS rest, mm (baseline) & $6(0-10)$ & $7(0-8)$ & $5(0-10)$ & 0.794 \\
\hline VAS rest, mm (2nd week) & $4(0-8)$ & $2(0-5)$ & 0.011 & 0.110 \\
\hline b $\mathbf{p}$ & 0.001 & $<0.001$ & $8(0-10)$ & - \\
\hline VAS night, mm (baseline) & $8(0-10)$ & $8(5-10)$ & $7(0-10)$ & 0.945 \\
\hline VAS night, mm (2nd week) & $4(0-10)$ & $3(0-7)$ & 0.005 & 0.017 \\
\hline $\mathbf{p}$ & $<0.001$ & $<0.001$ & $7(3-10)$ & - \\
\hline VAS activity, mm (baseline) & $8(1-10)$ & $8(0-10)$ & $6(3-10)$ & 0.947 \\
\hline VAS activity, mm (2nd week) & $5(0-9)$ & $3(0-8)$ & 0.005 & 0.001 \\
\hline $\mathbf{p}$ & $<0.001$ & $<0.001$ & $55(28-75)$ & - \\
\hline Q-DASH (baseline) & $60(29-90)$ & $67(38-80)$ & $48(23-71)$ & 0.023 \\
\hline Q-DASH (2nd week) & $30(0-65)$ & $25(0-80)$ & 0.001 & 0.001 \\
\hline $\mathbf{p}$ & $<0.001$ & $<0.001$ & $2(0-52)$ & - \\
\hline $\begin{array}{l}\text { cQ-DASH pre-post } \\
\text { (difference) }\end{array}$ & $30(0-53)$ & $38(0-59)$ & $<0.001$ \\
\hline $\begin{array}{l}\text { VAS: Visual analogue scale, Q-DASH: The disabilities of the arm, shoulder and hand questionnaire, KT: Kinesiotaping, CE: Conventional exercise, min: Minimum, max: } \\
\text { Maximum, akruskal-Wallis test, bWilcoxon Signed Rank test, cPost-hoc analysis-Bonferroni test }\end{array}$ & \\
\hline
\end{tabular}


whether the post-treatment changes in these measurements differed between the groups. A significant difference was found between the groups for both parameters. According to post-hoc analyses, there was a statistically significant difference between the sham-KT and CE groups and between the KT and CE groups in favor of the CE group in terms of SST thickness decrease $(p<0.016)$. In terms of AHD increase, there was a significant difference between the sham-KT and KT groups and the sham-KT and CE groups in favor of the KT and CE groups $(p<0.016)$ in Table 4.

\section{Discussion}

Assessments were made of pain, functionality, ROM, physical examination findings, SST thickness and AHD in patients with SIS and it was observed that the application of $\mathrm{KT}$ resulted in significant improvements in all parameters. CE is reportedly effective as a treatment for pain, ROM, and functionality in patients with SIS $(13,14)$. Therefore, the aim of this study was to investigate the efficacy of KT application in comparison with not only sham-KT application but also with CE, which is known to be effective in patients with SIS. KT is frequently used as a component of rehabilitation programs for SIS and rotator cuff tendinitis (15). In these pathologies, the primary aim is to reduce edema and pain and increase the ROM and muscle activity. Studies have shown that KT reduces pain in patients with SIS and increases the joint ROM, particularly in the early period (1619). Thelen et al. (18) assessed the efficacy of KT application on pain, disability, and painless active joint ROM in patients with SIS or rotator cuff tendinitis. KT showed a similar effect to that of sham-KT in all parameters except for painless shoulder ABD. In contrast, Şimşek et al. (19) compared the efficacy of KT and sham-KT in patients with SIS and found that KT was superior to the sham-KT group in terms of pain and functionality. In this study, CE treatment was applied to both groups. Kaya et al. (20) compared KT and manual therapy in patients with SIS in terms of disability and pain and reported that compared with manual

Table 3. Comparison of joint range of motion measurements at pre- post-treatment visit

\begin{tabular}{|l|l|l|l|l|}
\hline \multirow{2}{*}{ Parameters } & KT group (n=25) & EX group (n=25) & Sham-KT group (n=25) & ap \\
\cline { 2 - 5 } & Median (min-max) & Median (min-max) & Median (min-max) & $150(120-180)$ \\
\hline FLX, degree (baseline) & $180(90-180)$ & $180(90-180)$ & $160(120-180)$ & 0.680 \\
\hline FLX, degree (2nd week) & $180(140-180)$ & $180(120-180)$ & 0.011 & 0.001 \\
\hline b $\mathbf{P}$ & 0.003 & 0.003 & $150(80-180)$ & - \\
\hline ABD, degree (baseline) & $150(80-180)$ & $130(90-180)$ & $150(90-180)$ & 0.484 \\
\hline ABD, degree (2nd week) & $170(90-180)$ & $180(140-180)$ & 0.017 & 0.007 \\
\hline $\mathbf{p}$ & 0.003 & $<0.001$ & $70(40-70)$ & - \\
\hline IR, degree (baseline) & $70(20-90)$ & $70(20-70)$ & $70(40-70)$ & 0.600 \\
\hline IR, degree (2nd week) & $70(40-90)$ & $70(40-70)$ & 0.317 & 0.556 \\
\hline $\mathbf{p}$ & 0.041 & 0.007 & $90(40-90)$ & - \\
\hline ER, degree (baseline) & $90(30-90)$ & $90(30-90)$ & $90(40-90)$ & 0.140 \\
\hline ER, degree (2nd week) & $90(60-90)$ & $90(40-90)$ & 0.317 & - \\
\hline $\mathbf{p}$ & 0.018 & 0.066 & & -008 \\
\hline $\begin{array}{l}\text { FLX: Flexion, ABD: Abduction, IR: Internal rotation, KT: Kinesiotaping, ER: External rotation, min: Minimum, max: Maximum, akruskal-Wallis test, bWilcoxon Signed Rank } \\
\text { test }\end{array}$ & & \\
\hline
\end{tabular}

Table 4. Comparison of ultrasonographic measurements at pre- post-treatment visit

\begin{tabular}{|c|c|c|c|c|}
\hline Ultrasound measurements & $\begin{array}{l}\text { KT group } \\
(n=25)\end{array}$ & $\begin{array}{l}\text { CE group } \\
(n=25)\end{array}$ & $\begin{array}{l}\text { Sham-KT group } \\
(n=25)\end{array}$ & $\mathbf{p}$ \\
\hline SsT thickness, mm median (min-max) (baseline) & $6.6(5.3-8.8)$ & $7.6(4.2-13)$ & $7.3(5-12)$ & 0.043 \\
\hline SsT thickness, mm median (min-max) (2nd week) & $6.6(5-8.8)$ & $7.5(4.2-13)$ & $7(5-12)$ & 0.099 \\
\hline p & 0.024 & $<0.001$ & 0.017 & - \\
\hline AHD, mm median (min-max) (baseline) & $11.7(9.8-16.7)$ & $13.5(9.9-16.3)$ & $13(11.1-16.4)$ & 0.020 \\
\hline AHD, mm median (min-max) (2nd week) & $12(10-16.7)$ & $13.8(10.5-16.6)$ & $13(11.1-16.4)$ & 0.022 \\
\hline p & 0.002 & $<0.001$ & 0.577 & - \\
\hline cSsT Thickness, mm (baseline -2nd week difference) & $-0.2(0-0.5)$ & $0(0-0.4)$ & $0(0-0.3)$ & 0.002 \\
\hline AHD, mm (baseline -2nd week difference) & $0.2(-1-0.2)$ & $0(-0.4-0.4)$ & $0(0-0.9)$ & $<0.001$ \\
\hline
\end{tabular}


therapy, KT had a considerable effect on pain reduction after the first week of treatment initiation, although both groups showed similar improvements in the pain and functionality parameters after the second week. In the current study, both groups received CE treatment. Kaya et al. (20) considered this early pain reduction effect observed with $\mathrm{KT}$ to be a positive advantage because it would also increase the performance of CE application. In the current study, considerable improvements were observed in the pain and disability scores of all three groups. When the groups were compared in terms of pain scores, it was observed that the CE group but not the KT group was superior to the shamKT group. A significant improvement was also observed in the functionality scores in all three groups, and the improvements in both the $\mathrm{KT}$ and $\mathrm{CE}$ groups were determined to be superior to those of the sham-KT group.

There are certain theories explaining the role of $\mathrm{KT}$ in pain relief. The first theory is the reduction of subcutaneous nociceptor pressure in the skin. KT also provides afferent stimulation on soft tissue. Thus, the gate control mechanism is activated with afferent feedback. By regulating superficial and deep fascia functions, it reduces edema and inflammation, thereby producing analgesic effects $(17,21)$. In the current study, the pain parameters in the sham-KT group also showed improvement. Sham-KT applied to the same muscle can produce analgesic effects because of the appropriate sensory feedback during the movement of the muscle. This in turn reduces mechanical irritation in soft tissues $(22,23)$. Furthermore, this sensory feedback simultaneously increases patient awareness and compliance with ergonomic principles $(17,21)$. Therefore, sham-KT application is recommended using a different band or to a different area. However, application to a different area may disrupt the blinding process of a study. Using tapes with different characteristics would be more suitable in prospective studies. Of the aforementioned studies related to SIS, only the study conducted by Thelen et al. (18) directly compared isolated KT and sham-KT applications. In other studies, the patients were also administered CE treatment, which eliminates the chance of observing the isolated effect of KT application on pain and functionality. The limitation of the study by Thelen et al. (18) was that it did not compare KT application with another treatment method with proven efficacy in terms of evidence-based medicine. In the current study, this limitation was considered and a third group was treated with CE therapy alone, as it has proven efficacy on SIS. The results of this study, which directly compared KT application with CE treatment, concluded that KT is as effective as CE in terms of improving the pain scores and shoulder disability index.

The current study results showed an increase in all joint ROM parameters in the KT group. In terms of the joint ROM, the ABD angles were found to be significantly higher in the CE group than in the sham-KT group. In the sham-KT group, the FLX and ABD angles showed improvement. The strengthening of the motor unit caused by an increased proprioceptive stimulus by the tape and a subsequent increase in motion may lead to an increase in the $A B D$ angle $(17,24)$. The improvements in the joint ROM can be considered to have occurred through the restoration of damaged and irregular fascia by KT application and pain relief. Fascial correction with KT allows the fascia movements to be guided to the desired direction and alignment (25). From the results of the current study, it was thought that the shoulder was guided to the glenohumeral motion arch with the applied KT method, and that there was a simultaneous reduction in mechanical irritation in the affected soft tissue structures, leading to increased joint $\operatorname{ROM}(26,27)$.

The AHD and SsT thickness measurements were also evaluated using US. Michener et al. (12) also used US to evaluate SsT thickness and AHD in patients with SIS and reported SsT thickness as $6.6 \mathrm{~mm}$ and AHD as $10.8 \mathrm{~mm}$. In the control group, SsT thickness and AHD were measured as 6 and $11.4 \mathrm{~mm}$, respectively. In previous studies investigating patients with SIS, SST thickness has been observed to be between 5.6 and $8.1 \mathrm{~mm}$. In the current study, the pretreatment SsT thickness measured using US was $7.1 \mathrm{~mm}$, which is consistent with values reported in literature. Pretreatment AHD was measured as $12.7 \mathrm{~mm}$, which was slightly higher than the value reported by Michener et al (12). In two previous studies, SsT thickness was found to be 1.1$1.5 \mathrm{~mm}$ thicker than in the control group $(28,29)$. Kaya et al. (20) compared KT and manual therapy in patients diagnosed with SIS, evaluated SST thickness with pre-treatment and post-treatment US, and found no significant changes. In the current study, a decrease in SsT thickness was detected in all three groups. When the groups were compared, the reduction was found to be considerably higher in the KT group than in the sham-KT group. Pre-treatment AHD measurements were 13, 11.7, and $13.5 \mathrm{~mm}$ (mean, $12.7 \mathrm{~mm}$ ), whereas post-treatment AHD measurements were 13,12 , and 13.8 $\mathrm{mm}$ (mean, $12.9 \mathrm{~mm}$ ). AHD was significantly increased in the CE and KT groups. To the best of our knowledge, no other study has yet evaluated AHD using US before and after treatment in patients with SIS. Therefore, this study, in which SsT thickness and AHD were evaluated using US before and after treatment in patients with SIS, can be considered to contribute to the literature. The decrease in SsT thickness and the increase in AHD were considerably higher in the CE group than in the other groups, which was thought to be due to the effect of the CE program administered to patients at the time of SIS diagnosis. Strengthening of the muscles providing glenohumeral stabilization eliminated the strain on the supraspinatus muscle, thereby decreasing tendinitis symptoms, and this was observed as a decrease in the tendon thickness in the US measurements. The increase in AHD observed in the KT group was attributed to the effect of the inhibition technique applied to the deltoid muscle, which elevated the humerus, and the mechanical correction technique, which restored the protracted position of the shoulder. 


\section{Study Limitations}

Limitations of the study; patients were evaluated at baseline and at 2 weeks after treatment only and there was no follow-up evaluation.

\section{Conclusion}

The results of this study demonstrated that with the exception of the pain parameter, KT was superior to sham-KT in patients with SIS in all the other parameters. It was also found to be as effective as CE in terms of all parameters. In addition, the US measurements performed in this study objectively revealed that tendinitis in the supraspinatus could be relieved and that AHD could be increased. KT is an alternative treatment option in patients with SIS and can be used alone as well as safely in combination with $\mathrm{CE}$.

\section{Ethics}

Ethics Committee Approval: Approval for the study was granted by the Haydarpaşa Numune Training and Research Hospital Clinical Research Ethics Committee (decision no: HNEAH-KAEK 2016/98).

Informed Consent: All patients provided written consent prior to study initiation.

Peer-review: Externally and internally peer-reviewed.

\section{Authorship Contributions}

Surgical and Medical Practices: F.B., D.G.K., N.M., M.H.T., Concept: F.B., D.G.K., N.M., M.H.T., Design: F.B., D.G.K., N.M., M.H.T., Data Collection or Processing: F.B., M.H.T., Analysis or Interpretation: F.B., D.G.K., N.M., M.H.T., Literature Search: F.B., D.G.K., Writing: F.B., D.G.K.

Conflict of Interest: No conflict of interest was declared by the authors

Financial Disclosure: The authors declared that this study received no financial support.

\section{References}

1. Bagcier F, Külcü Geler D, Yorulmaz E, Altınok EÇ. Intra-and interrater reliability of ultrasound measurements of supraspinatus tendon thickness, acromiohumeral distance, and occupation ratio in patients with shoulder impingement syndrome. Arch Rheumatol 2020;35:385-93

2. Özsoy $\mathrm{MH}$, Fakığlu $\mathrm{O}$, Aydoğan $\mathrm{NH}$. Subacromial impingement syndrome. Acta Orthop Traumatol Turc 2013;340-52.

3. Clausen MB, Bandholm T, Rathleff MS, Christensen KB, Zebis MK Graven-Nielsen T, et al. The Strengthening Exercises in Shoulde Impingement trial (The SExSI-trial) investigating the effectiveness of a simple add-on shoulder strengthening exercise programme in patients with long-lasting subacromial impingement syndrome: Study protocol for a pragmatic, assessor blinded, parallel-group, randomised, controlled trial. Trials 2018;19:154

4. Petri M, Hufman SL, Waser G, Cui H, Snabes MC, Verburg KM. Celecoxib effectively treats patients with acute shoulder tendinitis/ bursitis. J Rheumatol 2004;31:1614-20

5. Dong $\mathrm{W}$, Goost $\mathrm{H}$, Lin XB, Burger $\mathrm{C}$, Paul $\mathrm{C}$, Wang $Z \mathrm{~L}$, et al Treatments for shoulder impingement syndrome: a PRISMA systematic review and network metaanalysis. Medicine (Baltimore) 2015:94:e510. doi: 10.1097/MD.0000000000000510.
6. Mostafavifar M, Wertz, J, Borchers J. A systematic review of the effectiveness of kinesio taping for musculoskeletal injury. Phys Sports Med 2012;40:33-40.

7. Reneker JC, Latham L, McGlawn R, Reneker MR. Effectiveness of kinesiology tape on sports performance abilities in athletes: a systematic review. Phys Ther Sport 2018;31:83-98.

8. Kul A, Ugur M. Comparison of the Efficacy of conventional physical therapy modalities and kinesio taping treatments in Shoulder Impingement syndrome. Eurasian J Med 2019;51:139-44.

9. Kinesiotaping method. KinesioTaping Association International Website 2015. Available from: http://www.kinesiotaping.com/ about/kinesio-taping-method. Accessed February 25.

10. Çelik D, Akyüz G, Yeldan i. Comparison of the effects of two different exercise programs on pain in subacromial impingement syndrome. Acta Orthop Traumatol Turc 2019;43:504-9.

11. Düger T, Yakut E, Öksüz Ç, Yörükan S, Bilgütay BS, Ayhan Ç, et al. Reliability and validity of the Turkish version of the Disabilities of the Arm, Shoulder and Hand (DASH) questionnaire. Turk J Phys Med Rehab 2006;17:99-107.

12. Michener LA, Subasi Yesilyaprak SS, Seitz AL, Timmons MK, Walsworth MK. Supraspinatus tendon and subacromial space parameters measured on ultrasonographic imaging in subacromial impingement syndrome. Knee Surg Sports Traumatol Arthrosc 2015;23:363-9.

13. Ozsahin M, Akgün K, Aktaş I, Kurtaiş Y. Adaptation of the Shoulder Disability Questionnaire to the Turkish population, its reliability and validity. Int J Rehabil Res 2008;31:241-5.

14. Michener LA, Walsworth MK, Burnet EN. Effectiveness of rehabilitation for patients with subacromial impingement syndrome: a systematic review. J Hand Ther 2004;17:152-64.

15. Kocyigit F, Acar M, Turkmen MB, Kose T, Guldane N, Kuyucu E. Kinesio taping or just taping in shoulder subacromial impingement syndrome? A randomized, double-blind, placebo-controlled trial. Physiother Theory Pract 2016;32;501-8.

16. Celik D, Akyuz G, Yeldan i. Comparison of the effects of two different exercise programs on pain in subacromial impingement syndrome. Acta Orthop Traumatol Turc 2009;43:504-9.

17. Kaya E, Zinnuroglu M, Tugcu I. Kinesio taping compared to physical therapy modalities for the treatment of shoulder impingement syndrome. Clin Rheumatol 2011;30:201-7.

18. Thelen MD, James AD, Paul DS. The clinical efficacy of kinesio tape for shoulder pain: a randomized, double-blinded, clinical trial. J Orthop Sports phys Ther 2008:3389-395.

19. Şimşek HH, Balki S, Keklik SS, Öztürk H, Elden H. Does Kinesio taping in addition to exercise therapy improve the outcomes in subacromial impingement syndrome? A randomized, double-blind, controlled clinical trial. Acta Orthop Traumatol Turc 2013;47:10410.

20. Kaya DO, Baltacı G, Toprak U, Atay AO. The clinical and sonographic effects of kinesiotaping and exercise in comparison with manual therapy and exercise for patients with subacromial impingement syndrome: a preliminary trial. J Manipulative Physiol Ther 2014;37:422-32.

21. Williams S, Whatman C, Hume PA, Sheerin K. Kinesio taping in treatment and prevention of sports injuries. Sports Med 2012;42;153-64.

22. Saavedra-Hernández M, Arroyo-Morales M, Cantarero-Villanueva I, Fernández-Lao C, Castro-Sánchez AM, Puentedura EJ, et al. Short-termeffects of spinal thrust joint manipulation in patients with chronic neck pain: a randomized clinical trial. Clin Rehabil 2013:27:504-12

23. Shakeri $H$, Keshavarz R, Arab AM, Ebrahimi I. Clinical effectiveness of kinesiological taping on pain and pain-free shoulder range of motion in patients with shoulder impingement syndrome: a randomized, double blinded, placebo-controlled trial. Int J Sports Phys Ther 2013;8:800-10.

24. Pekyavas, NO, Baltaci G. Short-term effects of high-intensity laser therapy, manual therapy, and Kinesio taping in patients with subacromial impingement syndrome. Lasers Med Sci 2016:31:1133-41. 
25. Lyman KJ, Keister K, Gange K, Mellinger CD, Hanson TA Investigating the effectiveness of kinesio ${ }^{\circledR}$ taping space correction method in healthy adults on patellofemoral joint and subcutaneous space. Int J Sports Phys Ther 2017;12:250-7.

26. Kase K, Wallis J, Kase T. Clinical therapeutic applications of the kinesio taping method. 3rd ed. Tokyo: Ken Ikai Co. Ltd; 2003.

27. Dias EM, Portella G, Lemos TV. Bandagens e imobilizadores. profisio esportiva Traumato- Ortopedica 2012;1:89-155.
28. Cholewinski JJ, Kusz DJ, Wojciechowski P, Cielinski LS, Zoladz MP. Ultrasound measurement of rotator cuff thickness and acromiohumeral distance in the diagnosis of subacromial impingement syndrome of the shoulder. Knee Surg Sports Traumatol Arthrosc 2008;16:408-14.

29. Leong HT, Tsui S, Ying M, Leung VY, Fu SN. Ultrasound measurements on acromio-humeral distance and supraspinatus tendon thickness: test-retest reliability and correlations with shoulder rotational strengths. J Sci Med Sport 2012;15:284-91. 